\title{
Cognitive Mapping of Organic Vegetable Production in Flanders to Support Farmers Strategy Design
}

Strubbe M.1, Bijttebier J.1, Van Meensel J. 1, Marchand F.1,2 and Lauwers L. 1,3

1 Institute for Agricultural and Fisheries Research, Social Sciences Unit, Merelbeke, Belgium

2 University of Antwerp, Ecosystem Management Research Group and IMDO, Belgium

3 Ghent University, Department of Agricultural Economics, Belgium

Keywords: agricultural production system, organic agriculture, systems approach, decision making, qualitative modelling

\begin{abstract}
Organic farmers inherently have to cope with complex agricultural production system processes. Next to pursuing economic performance, farm management also encompasses optimization of the farm's ecological and social performance. The question rises on how to maintain a certain balance between the multiple purposes. For this consideration, the farmer and as well researcher need to understand the logic of the system. To support decisions, this study aims at modelling the key elements and their inter-relations for successful organic vegetable production in Flanders. For this research a model was constructed based on the qualitative cognitive mapping technique. Cognitive mapping can be used to develop maps of socio-ecological systems based on people's knowledge of ecosystems (Özesmi and Özesmi, 2004 and Fairweather, 2010). Different stakeholder groups (advisors, farm networks, research and educational institutions) were interviewed in order to represent and visualize their expert knowledge. Through in-depth interviews, experts were questioned on the key elements of a successful organic farm management and how these aspects relate to each other. Next, the individual cognitive maps from the different interviewees were merged to build a social cognitive map. The social cognitive map represents the perception of the stakeholders on the agricultural production system. Preliminary results show the social cognitive map covers a broad range of key elements (economic, agro-technical and biophysical factors, next to a few social factors) The central aspects within the agricultural production system, determining the structure, are crop choice, crop rotation, marketing and technology and mechanization.
\end{abstract}

\section{INTRODUCTION}

Farmers 'decisions are based on a wide range of factors related to a complex agricultural production system they take part in (Vanwindekens et al., 2013; Fairweather, 2008; Edwards et al.,1999; Landais et al.,1988). This complex socio-ecological system (Fairweather, 2008) is defined as a combination of cropping/livestock systems at the farm level which use different inputs as labor, land, equipment, knowledge and capital resources over time and space to produce goods and ecosystem services (Boiffin et al., 2004). Moreover, this system is dynamic with many linear but also non-linear interrelations between the different components which are of natural, technical but also human nature. This complexity of the agricultural production system makes decision making by the farmer difficult. In addition the outcome often remains uncertain and unpredictable. Even more complexity is faced, as farmers often pursue multiple goals. Next to an economic purpose farmers can as well pursue social, 
biophysical and ecological purposes (Ten berge et al., 2000). Farmers usually seek an optimal compromise between several conflicting objectives (Gasson 1973, Harper and Eastman 1980). For example, trying to sustain sufficient economic productivity for providing an income, can be combined with reducing inputs that have environmental externalities on- and off-farm (Edwards et al.,1999). Agricultural production systems therefore need to be designed that can manage multiple and often contradictory objectives (Le gal et al., 2010).

In order to manage this complex decision making, a good understanding of the agricultural production system is needed. In reality understanding of the complexity of this agricultural production system is often incomplete (Walker, 2000). Providing insight into the complexity of the system might however help farmers to understand the impact and logic of their decision making process. Moreover, systems insight can support the farmer in their daily farming practice and in their search for responses to a rapidly changing socio-economic environment surrounding the agricultural production system (Le gal et al.,2010; Bolte et al.,2007, Darnhofer et al., 2012).

The objective of this paper is to visualize the agricultural production system and its complexity to support a better understanding. This study focuses on the organic production of vegetables in Flanders for the following reasons. The organic farming sector in particular holds a strong system complexity, as organic farmers 'decisions have certain ecological, social and economic dimensions. Although the sector is confronted with a demand side that exceeds the supply side, this does not stimulate conventional farmers to switch towards organic production. Both social and psychological barriers, market structure, farm economics and the need for further technological development might explain this lack of interest (Kerselaers et al., 2005). On top scientific data, certainly quantitative knowledge, is strongly lacking for the sector.

To better understand the main challenges and difficulties confronting this sector and more important, how these are interrelated we searched for a system approach. Although holistic and system approaches gain more attention in research, Knickel et al. (2008) state that more and more knowledge of agriculture is disconnected from everyday farming practice, resulting in a system description which insufficiently reflects farm level realities. Including stakeholders and farmers themselves in a system approach might help decrease the disconnection with reality (Knickel et al., 2008). To include local farmers 'knowledge in achieving our goal, we decided to use the cognitive mapping approach.

The paper starts with describing how the cognitive mapping approach can be useful in general and how it is used in this research. In section 3 the cognitive maps are presented and analyzed. Section 4 discusses (1) the utility of the cognitive map for describing the system and (2) the completeness of the system description.

\section{METHODOLOGY}

\section{Cognitive mapping in general}

The cognitive map is a representation of how a person perceives a certain environment, problem or system. It focusses on how a complex problem can be solved or managed and secondly it helps structuring the problem. This structure is determined by a network of nodes and arrows. Nodes, generally short pieces of text, are linked to each other by arrows. The direction of the arrow indicates the perceived causality which makes for the differentiation between more goal-type and cause-type statements. This doesn't necessarily implicates a clear means/ends hierarchy, because circularity through loops can be as well structural 
characteristic of the map (Eden et al., 2004). Generally the maps are derived through interviews. There are individual and social maps: the individual map represents the perception of the system by one person, the social map represents the perception of a group of people (Eden et al., 2004). Two advantages vote in favor of the use of this technique. First the cognitive map is able to hold an unlimited complexity. Moreover, it is not necessary for the concepts to be well defined before starting the interview, which gives a certain degree of freedom to the interviewees. Secondly, being a qualitative technique, it is possible to construct the maps based on people's knowledge. Therefore there is no need for scientific data (Özesmi and Özesmi, 2004).

\section{Application mapping method for the case-study}

For this study, 21 stakeholders (12 farmers, 4 experts, 2 advisers and 3 researchers) from the arable agriculture and horticulture organic farming sector in Flanders were interviewed. They were selected through random selection and snowball sampling. Data were collected through open-ended interviews. The general question posed to the interviewee was to enumerate the key elements influencing the success of the agricultural production system. Further elaboration on each of these key elements, revealed more thorough information on how these key elements are positively or negatively interrelated. Moreover, additional influencing factors could be revealed. In a second step the interviews were coded using Nvivo 9 software. Coding consisted of identifying key elements and influencing factors as nodes. The relations between key elements and influencing factors were coded as well. Triangulation was achieved by coding of the first interviews by two persons.

For every interviewee an individual cognitive map was constructed out of the coded key elements, influencing factors and relations. These were subsequently augmented to social cognitive maps. When combining individual maps, each individual map is equally valid and has a weight of one. The cognitive map in itself is a complex web of nodes and relations. To analyze these maps the prevalence of nodes and relations within the map were compared. In order to have an overview on the most prevalent nodes and relations, they were ordered by number of interviewees mentioning the concept. Following the complexity of the map was analyzed. First a domain analysis was performed on the map, indicating the concepts with the most direct links to other concepts. Secondly centrality of concepts was determined. Central concepts are concepts that are related to many other concepts. Centrality gives an indication of how important the concept is within the whole structure. This analysis takes into account as well indirect links with a certain node, meaning successive layers of nodes indirectly linked to the analyzed node. (Özesmi and Özesmi,2004).

\section{Results}

\section{Key elements and influencing factors}

The open-ended interviews revealed a range of key elements influencing organic farm management. Key elements that appeared to contribute to a successful agricultural production system are of economic, environmental and social nature. Examples as labor, crop planning, marketing, soil and fertilization are aspects that farmers take into account when managing their farm. Fout! Verwijzingsbron niet gevonden.Table 1 presents the codebook and indicates the nature of the key elements and influencing factors resulting from the interviews. Five main categories were defined (Business, Soil, Fertilization, Crop, Environment) which each have different sub-categories. This was done for following reasons: to facilitate overview on the code list, to obtain a certain structure into the list and because the level of detail on 
which interviewees describe key elements differs. The different sub-categories agree with the different levels of detail interviewees handle. For example all 21 interviewees mention keyelement labor, but only 15 labor intensity, 6 labor cost, 14 labor planning, 4 job satisfaction, 11 labor availability. Information on the most referred key elements is indicated in Fout! Verwijzingsbron niet gevonden.Table 2.

\section{Cognitive maps}

Per interviewee an average of $30 \pm 9.1$ relationships could be indicated consisting out of an average of $32.9 \pm 7.2$ key elements. These relationships and key elements were mapped into the individual cognitive maps and consecutively augmented to a social cognitive map. The social cognitive map in Figure 1 gives an indication of the agricultural production system perceived by the stakeholders in the organic farming sector. There is a difference in thickness of the relations. The thickness indicates the number of interviewees quoting the relation. There are three categories: thickest (7-11 sources), middle thickness (6-5 sources) and thinnest (4 sources). Only those relations that are stated by at least 4 sources are visualized on the map, in order to simplify the visual interpretation. The map is arranged in a way that nodes from similar subjects are grouped as much as possible and the number of crossing arrows is minimized.

The domain analysis (Table 1) reveals that technology and mechanization has the most direct links. A second analysis is determining the centrality of concepts. The four nodes with the highest centrality scores are indicated in bold Figure 1. Marketing has a centrality score of 18 and crop planning, crop choice and technology and mechanization have a centrality score of 17 .

Our results show that stakeholders perceive crop choice and planning, marketing and technology and mechanization as determinative elements for a successful production system. They have an important share in determining the structure of the cognitive map through their strong interrelation with other key elements and influencing factors. Planning of the nature and the timing of the crops grown is one of the most central concepts. During crop planning, farmers indicate that they have to take into account many things such as weed pressure, conservation of good soil quality, a healthy crop rotation and how marketing is organized. Marketing is a non-negligible factor in farm management although farmers believe their impact on it is limited. Results show that marketing channels have a strong influence on product price and quality and uniformity standards. Farmers indicating that they do have a stronger influence on marketing, are more frequently short supply chain farmers. The choice of marketing channels is as well related to the crop choice. However, these crop choices differ strongly between the different farmers depending on the company size and farmer preference. Besides, crop choice is associated with the profitability of the chosen crop, the technology and mechanization present on the farm and the amount of labor that can potentially be available at the farm. Technology and mechanization is strongly interlinked with other aspects. Farmers believe optimal mechanization might ease weed control and reduce labor intensity and labor costs. However, they have to weigh out the investment and take in mind the farm size to be sure the investment is worthwhile.

\section{Discussion}

The social cognitive map covers a diverse range of factors, mostly economic, agrotechnical and biophysical factors, next to a few social factors. The perceived causality and 
association linking the different stated factors by the stakeholders gives a perception on the logic of the system. Possibly beneficial to attaining this diversity of factors was the diverse stakeholder involvement, not only limited to farmers. This assumption can be investigated through comparing group maps of the one hand experts, researchers and advisers and on the other hand the farmers. Future research will further focus on the possible contribution of expert opinion on the completeness of group maps.

Now further focusing on the social cognitive map (Figure 1), how do stakeholders perceive the complexity of the agricultural production system? First observation, derived from the data in Fout! Verwijzingsbron niet gevonden.Table 1, is that stakeholders agree on several decisive key elements in the agricultural production system, but only until a certain level of detail. Nearly every stakeholder mentions that for example technology and mechanization, finance, labor, crop planning and marketing play a decisive role in an agricultural production system. But when focusing further into detail on these more general key elements, stakeholders differ more strongly on their perception of important key elements. Interviews have learned farmers face different sometimes farm specific problems (bad soil quality, stronger influence of pest and disease, limited land availability). As for the experts interviews have learned experts go more into detail on the subjects they know the most of. So the level of perception of complexity differs between interviewees depending on among others the key element they perceive as most problematic. The social cognitive map combines these different perceptions of complexity, different levels of complexity and so can potentially hold a higher level of complexity. To further discuss into detail the complexity of the map more concretely, two key-elements are analyzed: marketing and technology and mechanization. More specifically the relatedness of these key elements is analyzed and what this can potentially mean for their relative importance. First stakeholders mention a strong correlation between marketing factors and other technological and ecological factors. Relatively more arrows are directed outwards from the elements marketing and marketing channel. Stakeholders indicate marketing is more influencing other key elements then the other way. Marketing seems to restrict farmers in making optimal decisions with respect to some other important key elements. Interviewees mention finding marketing for produced goods is very time consuming, among other due to a more lacking organization in comparison to conventional agriculture. The lack of an auction system for organic farmers makes they frequently they have to choose for more labor intensive marketing options as brokerage sales and direct marketing. The second relevant issue for many stakeholders, as the thickness of arrows indicates in the map (Fout! Verwijzingsbron niet gevonden.Figure 1), is how to manage the triangle weed control, labor and technology and mechanization. Results show that from these three factors technology and mechanization is the most central one. Technology and mechanization is a key element in handling the weed pressure and meanwhile reducing the related labor intensity. For this key element there is general agreement between experts and farmers: you need to mechanize as much as possible, to make farming financially and physically achievable. Stakeholders therefore believe that further technological innovations are important for the sector.

A side mark to these results is that the perceived important factors are not an absolute indicator of importance. Relations between factors that are not cited or only referred by one or two persons, can still be of absolute importance for the system functioning. For example only one farmer mentions the beneficial effects of communication and promotion on the profitability of a farm, although it might be possible that a good communication on website can be very beneficial for the marketing of the products. Moreover, it can be that the 
perception of relations by stakeholders is not consistent with reality. Fairweather (2010) states farmers can have a poor understanding of how their system works. If this is the case farmers local knowledge might not be sufficient to fully design the system based on their knowledge. Expert opinion can counteract this problem. For example seven interviewees mention the scale of the sector as a key element influencing farm management of which only two are farmers. The scale of the sectors is stated by the experts as key element in leading to different inefficiencies in the sector related to logistics, certainty of marketing, product price,... Concluding is that indicating absolute importance of key elements has to be handled with care. A consecutive useful step in this research therefore can be in using the social cognitive map for supporting discussions on key elements determining the agricultural production system. The map could be used to explain in a comprehensive way how the system works. In the same time these discussion groups can be used to validate the value and completeness of the group map and meanwhile start-up a learning process towards a better understanding of the logic of the system (Vanwindekens et al.,2013).

\section{Conclusion}

Our case study research confirms that the agricultural production system for organic farmers in Flanders is a complex issue. Through the cognitive mapping technique we were able to structure the complexity and gain insight into the logic of the system. Stakeholders have delivered a range of key elements of diverse nature. Results show a strong agreement between stakeholders on central key elements, being crop planning, crop choice, technology and mechanization and marketing. First three elements were indicated by the stakeholders as important tools for the farmer to get a grip on the system whereas the influence farmers have on marketing aspects was indicated as limited. Although the complexity of the system might not be fully captured, the delivered system description can certainly be useful to the stakeholders in for example supporting discussions on the complex decision making of farmers.

\section{Literature cited}

Boiffin, J., Hubert, B. and Durand, N. 2004. Agriculture et développement durable: Enjeux et questions de recherché. INRA Editions, Paris, France.

Bolte, J.P., Hulse, D.W., Gregory, S.V. and Smith, C. 2007. Modeling biocomplexityactors, landscapes and alternative futures. Environ Modell Softw, 22 (5): 570-579.

Darnhofer, I., Gibbons, D. and Dedieu, B. 2007. Farming Systems Research: An approach to inquiry. In: I. Darnhofer, D. Gibbons, B. Dedieu (Eds.) Farming Systems Research into the 21st century: The new dynamic. Springer Dordrecht, 1-30.

Eden, C. and Ackermann, F. 2004. Cognitive mapping expert views for policy analysis in the public sector. Eur J Oper Res, 152: 615-630.

Edwards, C.A., Grove, R.R., Harwood, R.R. and Pierce Colfer C.J. 1993. The role of agroecology and integrated farming systems in agricultural sustainability, Agric. Ecosyst. Environ., 46: 99-121.

Fairweather, J. 2010. Farmer models of socio-ecologic systems: application of causal mapping across multiple locations. Ecol. Model., 221: 555-562.

Francis, C., Lieblein, C., Gliessman, S., Breland, T.A., Creamer, N. ,Harwood, R., Salomonsson, L., Helenius, J., Rickerl, D. ,Salvador, R., Wiedenhoeft, M. , Simmons, S., Allen, P., Altieri, M., Flora, C. and Poincelot, R. 2003. Agroecology: 
The ecology of food systems. J. Sustainable Agric., 22 (3): $99-118$. Gasson, R. 1973. Goals and values of farmers. J Agr Econ. 24(3): 521-537. Harper, W.H. and Eastman, C. E. 1980. An evaluation of goal hierarchies for small farm Operators. Am J Agr Econ, 62(4), pp.742-747.

Kerselaers, E., Govaerts, W., Lauwers, L., DeCock, L. and Van Huylenbroeck, G. 2005. Modelling farm level economic potential for conversion to organic farming.

Proceedings of EAAE congress, Copenhagen, Denmark.

Landais, E., Deffontaines, J.P., Benoit, M. 1988. Les pratiques des agriculteurs point de vue sur un courant nouveau de la recherche agronomique. Etudes Rurales, 109:125-158.

Le gal, P.Y., Dugué, P., Faure, G. and Novak, S. 2010. How does research address the design of innovative agricultural production systems at the farm level? A review. Environ Modell Softw, 25: 258-268.

Özesmi, U. and Özesmi, S.L. 2004. Ecological models based on people's knowledge: a multi-step fuzzy cognitive mapping approach. Ecol Model, 176: 43-64.

Ten Berge, H.F.M., van Ittersum, M.K., Rossing, W.A.H., van de Ven, G.W.J., Schans, J. and van de Sanden, P.A.C.M. 2000. Farming options for The Netherlands explored by multi-objective modelling, European Journal of Agronomics, 13(2-3): 263-277.

Vanwindekens, F.M, Stilmant, D. and Baret, P.V. 2013. Development of a broadened cognitive mapping approach for analyzing systems of practices in social-ecological systems. Ecol.Model., 250:352-362.

Walker, D.H. 2002. Decision support, learning and rural resource management. Agr Syst, 73:113-127.

\section{$\underline{\text { Tables }}$}

Table 1: List of codes

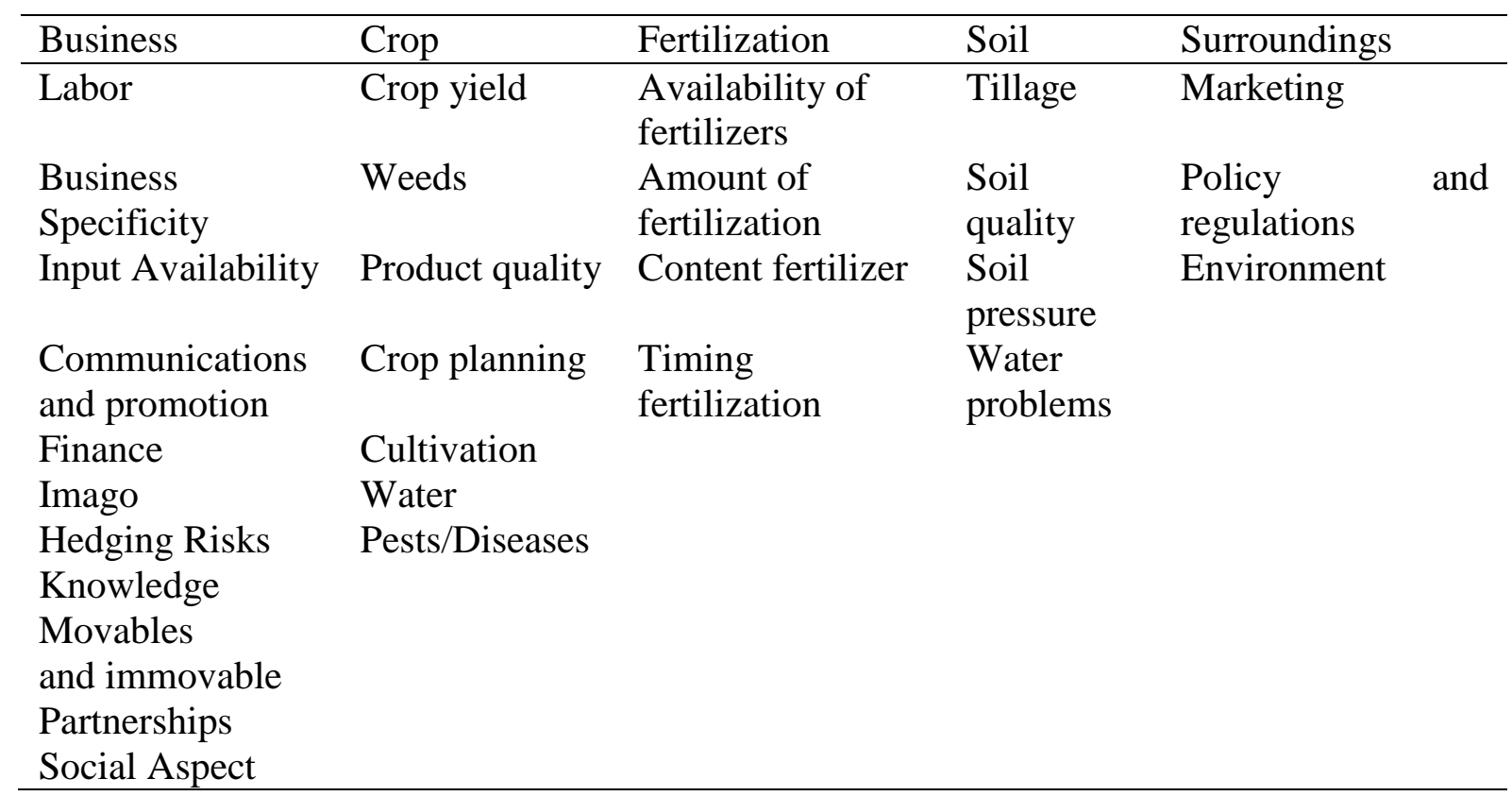


Table 2: 10 most referred key elements

\begin{tabular}{ll}
\hline Key elements & nr. of interviewees \\
\hline Labor & 21 \\
Crop planning & 21 \\
Sector & 21 \\
Marketing & 20 \\
Company specificity & 19 \\
Soil & 19 \\
Finance & 18 \\
Technology and mechanization & 18 \\
Fertilization & 18 \\
Pests / diseases & 18 \\
\hline
\end{tabular}

Table 1: Domain analysis

\begin{tabular}{ccc}
\hline 7 links around & 6 links around & 5 links around \\
\hline $\begin{array}{c}\text { Technology and } \\
\text { mechanization }\end{array}$ & Marketing & Crop planning \\
& $\begin{array}{c}\text { Marketing channel } \\
\text { Crop choice }\end{array}$ & Crop rotation \\
\hline
\end{tabular}

\section{$\underline{\text { Figures }}$}




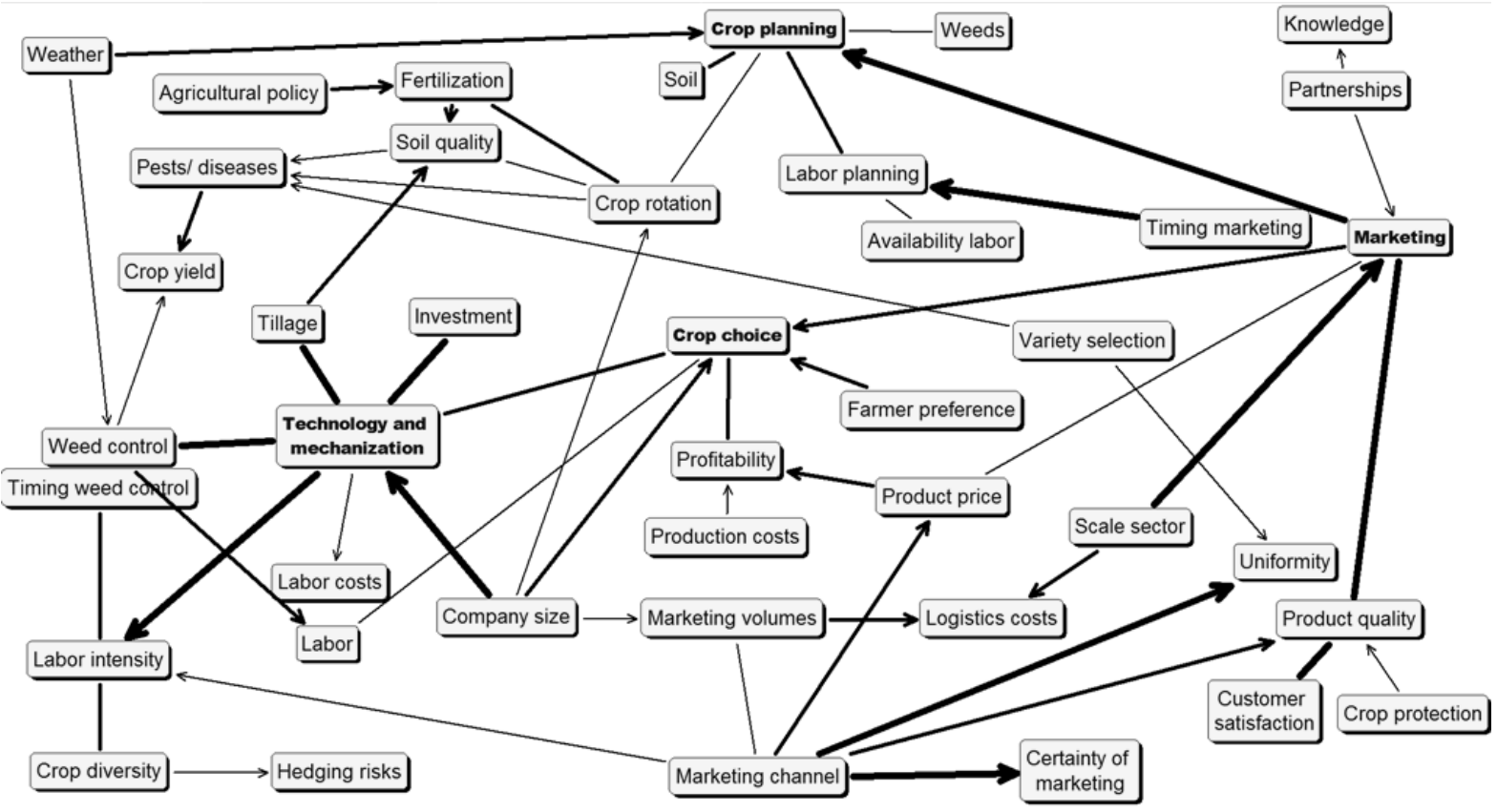

Fig.1. Social cognitive map 